on the plate is the same as that of the weaker for the same time of exposure, etc. For example, if this is achieved when the stronger beam has to be cut down to one-tenth (by a method which does not involve an intermittency effect), then it follows at once that the ratio of the original intensity of the stronger to that of the weaker is ro: I. Obviously the great advantage of this method is that it is independent of the kind of plate used, so that all the arduous work of calibration is avoided, and one depends for accuracy, so far as the photographic plate is concerned, only on the constancy of emulsion characteristics over a small portion of any single plate, a fact which must make for considerably greater accuracy. This method, of course, involves the cutting down of the intensity of the stronger beam in a known manner at all wavelengths, preferably by a " neutral " absorbing screen. No difficulty now seems to exist in regard to this, since successful methods have been used by various workers.

As has been stated, this note is prompted by the amount of work which is still being done on the calibration of certain types of commercial plates, presumably with the view of using them for the first method described above. In our opinion the second method is vastly to be preferred.

Physics Department,

F. C. Toy,

British Photographic Research Association, 3o Russell Square, W.C.I.

\section{Valence Theories and the Magnetic Properties of Complex Salts.}

I HAVE followed with considerable interest the discussion which has been recently carried on in Nature by Messrs. Jackson, Welo and Baudisch on the magnetic properties of the complex compounds of iron and other elements belonging to the first transition group. Two papers on this subject have recently been contributed by me, the first of which was sent in June to the Philosophical Magazine and deals with those complex compounds, the magnetic properties of which have been studied by Rosenbohm and Oxley. I have defined with Sidgwick the "effective atomic number $Z^{\prime}$ " of the co-ordinating atom in any complex compound, as the sum total of all the electrons contained in the former plus the number of electronic orbits which this atom shares with the neighbouring atoms and groups in the co-ordination compound. It can be shown that $Z^{\prime}=N-E+2 P$, where $N=$ atomic number of the co-ordinating atom, $E=$ its primary valency in the given compound and $P=4,6$, etc., according as the complex compound is either fourfold, sixfold, etc.; e.g. in the ferrous compound $K_{4}\left[\mathrm{Fe}(\mathrm{CN})_{6}\right]+3 \mathrm{H}_{2} \mathrm{O}, Z^{\prime}=26-2+2 \times 6=36$; while in the case of the fourfold compound of copper $\left[\mathrm{Cu}\left(\mathrm{NH}_{3}\right)_{4}\right]\left(\mathrm{NO}_{3}\right)_{2}, Z^{\prime}=29-2+2 \times 4=35$. These numbers can be independently calculated by the rule which has been given by Sidgwick.

In the above-mentioned paper I have shown that if $Z$ represents the atomic number of the inert gas which terminates any transition group of elements, e.g. in the case of the iron group the inert gas is krypton with $Z=36$, then all those co-ordination compounds, in which $Z^{\prime}=Z$, are diamagnetic, while the others are paramagnetic. This result agrees with that given by Messrs. Baudisch and Welo in their letter (NATURE, October 24, p. 606). In a second paper, which was written immediately after the publication of Mr. Welo's letter in NATURE (September 5, p. 359) and has been sent to the Zeitsch. $f$. Physik for publication, I have shown that the number of Bohr's magnetons contained in any co-ordination compound of the first transition group of elements, the magnetic properties of which have so far been studied, is given by $Z-Z^{\prime}$. The following table shows how the values of the magneton numbers, calculated according to the above rule, agree with the experimentally determined ones:

\begin{tabular}{|c|c|c|c|c|c|}
\hline \multirow{2}{*}{ Compound. } & \multicolumn{2}{|c|}{ Exp. Magneton No. } & \multicolumn{3}{|c|}{ Eff. At. No. } \\
\hline & Weiss's. & Bohr's. & $Z^{\prime}$. & $Z$. & $Z-Z^{\prime}$ \\
\hline$\left[\mathrm{Cr}\left(\mathrm{NH}_{3}\right)_{6}\right] \mathrm{I}_{3}$, & I9 & $3(\mathrm{rg} \cdot 2)$ & 33 & 36 & 3 \\
\hline$\left[\mathrm{Fe}(\mathrm{CN})_{6}\right] \mathrm{K}_{4}+3 \mathrm{H}_{2} \mathrm{O}$ & Dia & Dia & 36 & 36 & o \\
\hline$\left[\mathrm{Fe}(\mathrm{CN})_{6}\right] \mathrm{K}_{3}$ & ro & I $(8.6)$ & 35 & 36 & I \\
\hline $\left.\mathrm{Co}\left(\mathrm{NH}_{3}\right)_{6}\right] \mathrm{Cl}_{3}$ & Dia & Diá & 36 & 36 & o \\
\hline$\left[\mathrm{Ni}\left(\mathrm{NH}_{2}\right)_{4}\right] \mathrm{SO}_{4}$ & 13 & $2(\mathrm{I} 4 \cdot \mathrm{I})$ & 34 & 36 & 2 \\
\hline$\left[\mathrm{Ni}\left(\mathrm{NH}_{3}\right)_{6}\right] \mathrm{SO}_{4}$ & 16 & $2 \cdot 5(16 \cdot 7)$ & $3^{8}$ & 36 & 2 \\
\hline$\left[\mathrm{Cu}\left(\mathrm{NH}_{3}\right)_{4}\right]\left(\mathrm{NO}_{3}\right)_{2}$ & 9 & I $(8 \cdot 6)$ & 35 & 36 & I \\
\hline
\end{tabular}

I have placed in brackets next to the Bohr's magneton numbers, the equivalent number of Weiss's magnetons, calculated on the assumption that the co-ordinating atom is in the " $S$ " state. It will be seen that there is good agreement between the calculated and experimentally determined number of Bohr's magnetons contained in this class of co-ordination compounds. It remains to be seen whether further investigations will show that modifications are necessary. Incidentally, the above rule affords further evidence of the reality of Bohr's magnetons.

University College of Science,

D. M. Bose. Department of Physics,

92 Upper Circular Road, Calcutta, November 19 .

\section{Mendelian Genes and Rates of Development.}

Prof. J. S. Huxley and Mr. E. B. Ford have directed attention in NATURE of December $I_{2}$ to the developmental mechanism connecting the Mendelian gene and the visible character. A field for an attempt to learn something about this mechanism was suggested to me some little time ago by Prof. W. Garstang. Many problems of genetics, he pointed out, are connected with the hair and its colour in mammals, and therefore any process that is concerned in the distribution, development, or succession of hairs should be studied as minutely as possible.

My work has so far been confined to the mouse (Mus musculus). A study of the coat was first carried out as a piece of pure morphology in order to provide the necessary basis for the examination of the effects of known genes. A paper on this is shortly to appear. It will be enough to mention the following points. The hairs of the same region of the coat are of several types; the growth of a hair takes place entirely at the basal end, any individual hair taking about four weeks at the most to become fully formed; and, broadly speaking, all the hairs growing at the same time in any small area of the skin pass through much the same stage of development together.

At present I am occupied with the colour pattern of the wild mouse. Agouti, as is well known, is a simple dominant to black. Agouti differs from black in that some hairs have a sub-apical pale band that is in most cases yellow, though some are black throughout. As Prof. Garstang himself anticipated, there has proved to be a simple key to the agouti pattern. On the back of the mouse the presence or absence of the light band can be correlated with hair-type, and in types possessing the band its length and shade can

NO. 2933, VOL. II7] 